\title{
The value of morphofunctional magnetic resonance imaging with hepatospecific contrast agent in the characterization of hepatocellular carcinoma in a non-cirrhotic patient with hepatitis C
}

\author{
(D) Daniel Alvarenga Fernandes ${ }^{1}$ \\ (DD) Daniel Lahan Martins ${ }^{1}$ \\ (D) Thiago José Penachim ${ }^{\mathbf{1}}$ \\ Dicardo Hoelz de Oliveira Barros ${ }^{1}$ \\ (iD) Larissa Bastos Eloy da Costa \\ (i) Elaine Cristina de Ataíde ${ }^{3}$ \\ DIlka de Fátima Santana Ferreira Boin ${ }^{3}$ \\ (iD) Nelson Marcio Gomes Caserta ${ }^{1}$
}

\begin{abstract}
1. Departamento de Radiologia, Faculdade de Ciências Médicas da Universidade Estadual de Campinas (FCM-Unicamp), Campinas, SP, Brasil. 2. Departamento de Anatomia Patológica, Faculdade de Ciências Médicas da Universidade Estadual de Campinas (FCM-Unicamp), Campinas, SP, Brasil. 3. Unidade de Transplante de Fígado, Departamento de Cirurgia, Faculdade de Ciências Médicas da Universidade Estadual de Campinas (FCM-Unicamp), Campinas, SP, Brasil.
\end{abstract}

\section{SUMMARY}

Hepatocellular carcinoma in patients with hepatitis $C$ in the absence of cirrhosis is uncommon. We demonstrate the importance of morphofunctional magnetic resonance imaging (MRI) with a hepatospecific contrast agent by describing an asymptomatic female patient with HCV, who presented with a nodule detected on ultrasound. She underwent inconclusive computed tomography, presenting no signs of chronic liver disease. MRI with hepatospecific contrast providing functional information combined with the superior tissue contrast inherent to this method stands out for its greater accuracy with the possibility of not resorting to invasive diagnostic methods. With increasing experience and the dissemination of this new diagnostic modality in the medical field, its use and other potential benefits of morphofunctional MRI with hepatospecific contrast agents may be established, benefiting patients with challenging focal liver lesions.

KEYWORDS: Liver. Liver neoplasms. Contrast media. Diagnostic imaging. Magnetic resonance imaging.

\section{INTRODUCTION}

Although chronic infection by the hepatitis C virus (HCV) is one of the major risk factors for the development of hepatic cirrhosis and hepatocellular carcinoma (HCC), the emergence of HCC in patients with hepatitis $\mathrm{C}$ in the absence of cirrhosis, particularly after treatment and achievement of sustained virologic response, is uncommon ${ }^{1-3}$. A proper assessment of a focal liver lesion, interpreted initially as an indeterminate nodule by ultrasound (US) and/or computed tomography (CT) scans with contrast in a patient with HCV in the absence of cirrhosis has great therapeutic and prognostic importance. Due to the

DATE OF SUBMISSION: 19-Dec-2019

DATE OF ACCEPTANCE: 19-Jan-2020

CORRESPONDING AUTHOR: Daniel Alvarenga Fernandes

Rua Tessália Vieira de Camargo, 126, Cidade Universitária Zeferino Vaz, Campinas, SP, Brasil - 13083-887

Tel: +55 19 3521-7029

E-mail: daniel_alvafer@yahoo.com.br 
lack of descriptions with emphasis on imaging evaluation of indeterminate nodules in patients with HCV without cirrhosis, using magnetic resonance imaging (MRI) with a liver-specific contrast agent (LSCA), we are motivated to disclose the importance of this methodology in this particular scenario.

MRI is a well-established imaging method in clinical practice, producing images without ionizing radiation, with good spatial resolution and excellent tissue imaging, which allows for a very accurate assessment. The main innovations in this area are currently focused on improving anatomic resolution and, more recently, using molecular and functional methods. With the recent introduction in clinical practice, studies have demonstrated the use of the LSCA in morphofunctional imaging by MRI with a good safety profile (similar to the other conventional gadolinium contrast agents) ${ }^{4.5}$. The results of the use of this new contrast agent in MRI suggest a relevant impact on the definition of strategies for the approach of focal hepatic lesions, as well as in the assessment of the treatment employed ${ }^{4.5}$. However, due to its lower availability and higher cost in comparison with contrast CT and MRI with the conventional gadolinium contrast agent, its use is usually indicated for particular situations.

\section{CASE}

We describe a 46-year-old female patient, asymptomatic, HCV carrier, who presented with a nodule detected on the US. There were no co-infections by the human immunodeficiency virus (HIV), hepatitis B virus (HBV), and hepatitis D virus (HDV). CT was performed with inconclusive results (questionable arterial phase hyperenhancement) and no signs of chronic liver disease. MRI of the upper abdomen, before and after the administration of gadoxetic acid as a liver specific contrastagent (LSCA), detected a focal lesion of the liver in the segment VI, measuring $1.8 \mathrm{~cm}$ in the largest axis, with arterial phase hyperenhancement, venous washout, pseudocapsule, restriction to the diffusion of water molecules and hyposignal in the hepatobiliary phase, findings with characteristics of a small HCC (Figure 1). No other focal nodular lesions or signs of liver disease were identified. Histopathologic evaluation revealed small HCC since it measured less than $2.0 \mathrm{~cm}$ in diameter,

FIGURE 1. MRI USING A LIVER-SPECIFIC CONTRAST AGENT DEMONSTRATING CHARACTERISTICS OF THE HCC IN A NON-CIRRHOTIC LIVER. MILD T2 HIPERINTENSE, RESTRICTED DIFFUSION, ARTERIAL PHASE HYPERENHANCEMENT, CONTRAST AGENT WASHOUT, AND HYPOINTENSE IN HEPATOBILIARY PHASE. SIGNS OF DIFFUSE STEATOSIS (SIGNAL LOSS IN OUT-OF-PHASE SEQUENCE). *ADC - APPARENT DIFFUSION COEFFICIENT. ${ }^{* *}$ ARTERIAL SUB. - ARTERIAL SUBTRACTION. SOURCE: THE AUTHOR (2019).

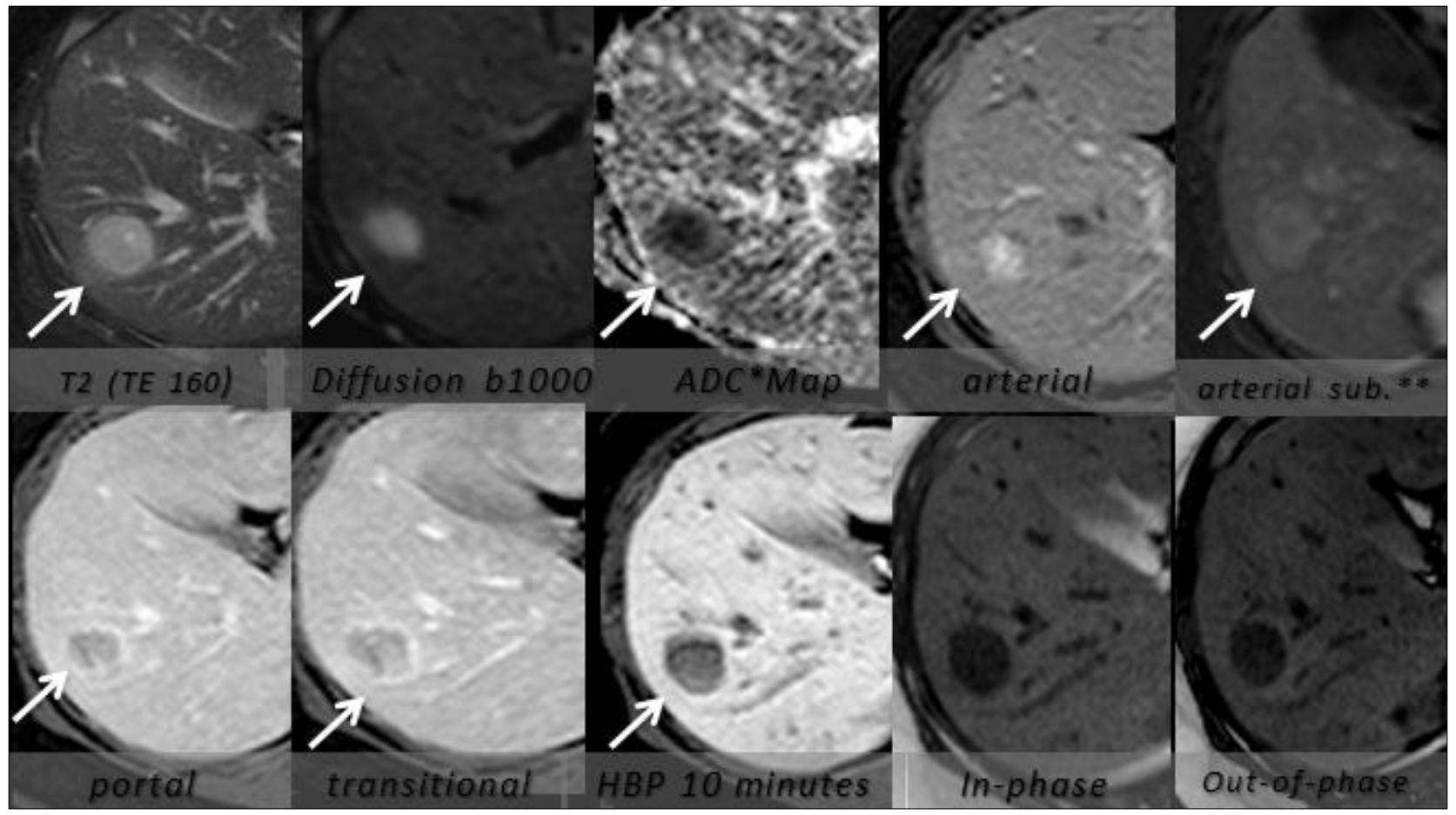


but already had well-defined peritumoral borders (Figure 2A).

The lesion showed exuberant perisinusoidal fibrous stroma, sometimes forming lamellae, with growth in irregular strings and atrophy of the neoplastic trabeculae, characterizing the cirrhosis variant of HCC, a rare presentation, occurring in less than $5 \%$ of cases, which seems to be associated with more aggressive behavior (Figure 2B). It is important to highlight that the fibrolamellar variant was excluded, since, despite the fibrous strings, the lesion was moderately differentiated (Edmondson-Steiner Grade 2) (Figure 2C) and had no neoplastic hepatocytes of an oncocytic pattern. The adjacent liver parenchyma had steatohepatitis with mild inflammatory activity, without architectural alterations of multifocal nodular transformation (non-cirrhotic liver) or other signs of chronic hepatopathy (Figure 2D). There was also no siderosis or other deposits upon the use of Perl's staining. The margin of surgical resection and Glisson capsule were free of neoplasia, and no carcinomatosis emboli, angiolymphatic or blood, were found. Currently, the patient is without complaints and in good general condition; she is undergoing outpatient follow-up for hepatitis C, without new detectable focal hepatic lesions.

\section{DISCUSSION}

The term "functional imaging" includes techniques capable of assessing in vivo physiological parameters of the tissues that provide additional useful clinical

FIGURE 2. FIGURE 2A. MACROSCOPY: NODULAR LESION OF WELL-DEFINED BORDERS, MEASURING $1.8 \times 1.8 \times 1.5$ CM, WHITISH AND HOMOGENEOUS, OF FIBROELASTIC CONSISTENCY. FIGURE 2B - MICROSCOPY (MASSON'S TRICHROME, 2OOX): CIRRHOTIC HCC, SHOWING DENSE FIBROUS LAMELLAE PERMEATING THE NEOPLASTIC HEPATOCYTES. FIGURE 2C - MICROSCOPY (HEMATOXYLIN-EOSIN, 2OOX): MODERATELY DIFFERENTIATED HCC, WITH IRREGULAR TRABECULAE OF NEOPLASTIC CELLS WITHOUT ONCOCYTIC CHARACTERISTICS, EXCLUDING FIBROLAMELLAR HCC. FIGURE 2D - NON-TUMORAL, NON-CIRRHOTIC HEPATIC PARENCHYMA WITH MACROVESICULAR STEATOSIS AND HEPATOCELLULAR BALLOONING IN ACINAR ZONE 3 (STEATOHEPATITIS).

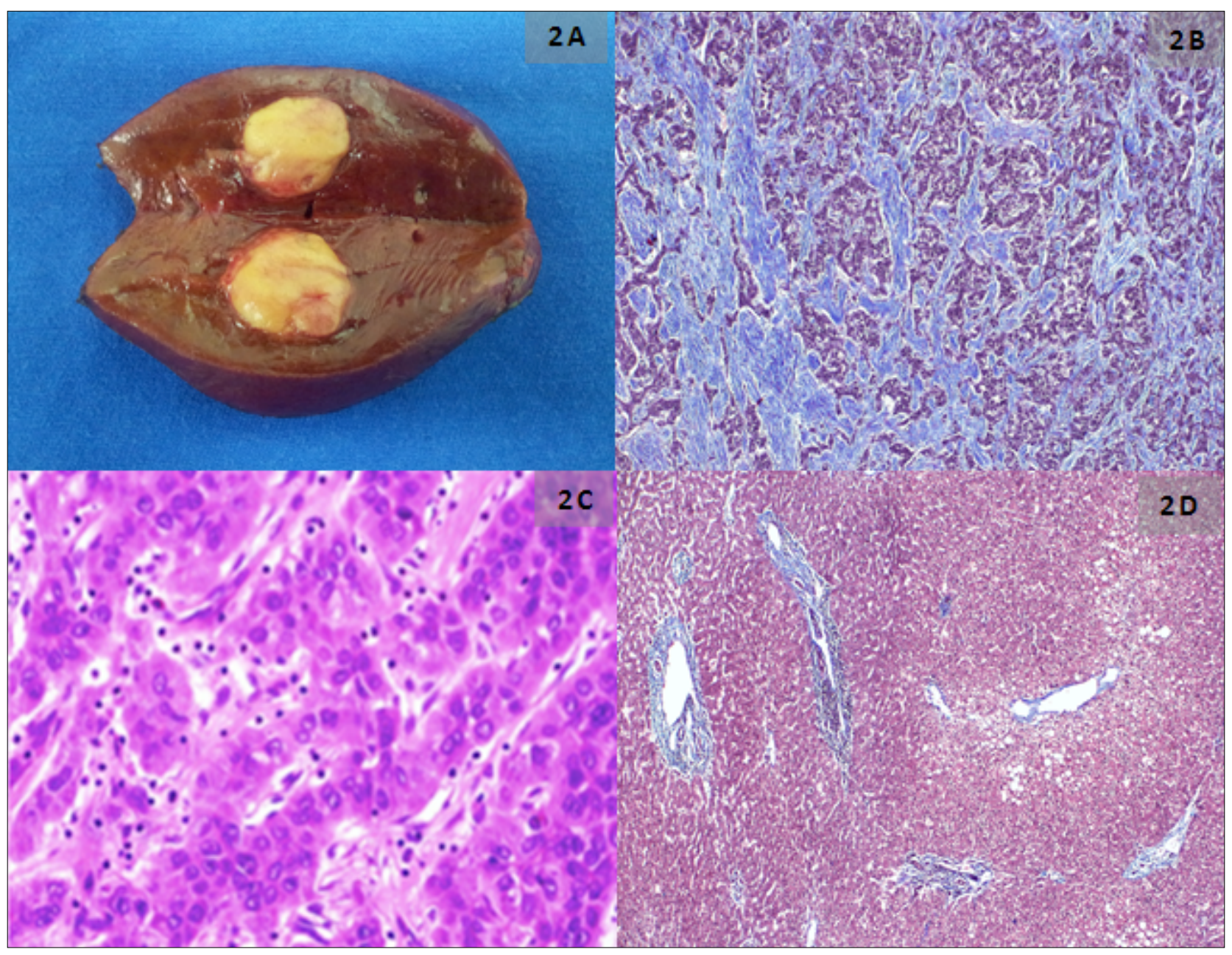


information to those obtained from imaging morphological data. It can be used in hepatology to detect and characterize tumors, in therapeutic choice, monitoring of therapeutic response, and patient follow-up ${ }^{6}$. There are four main functional imaging modalities used in liver assessment: 1 - Diffusion-weighted imaging (DWI), which refers to the random or "Brownian" movement of protons in water molecules through biological tissues - a marker of cellularity and microarchitecture; 2 - Contrast agents in ultrasound, computed tomography or MRI; 3 - Image of the hepatocellular function using LSCA; and 4 - Metabolic nuclear imaging using positron emission tomography (PET)/CT with radiotracers marked to assess specific metabolic pathways ${ }^{6}$. In this case, three of the four functional imaging modalities were used: diffusion-weighted imaging (DWI), dynamic vascular phases following contrast injection (arterial, portal and transitional phases) and hepatobiliary phase (hepatocellular function). This joint analysis provided more security in characterizing the liver injury, which was previously indefinitely as a suspected small HCC. The functional information combined with the superior tissue contrast inherent to the MRI, we have obtained greater accuracy ${ }^{7}$, with the possibility of not resorting to invasive methods. Differential imaging diagnoses could include metastases and other atypical lesions in this case. Protocols and guidelines drawn up in a joint effort by major scientific societies have pointed to the inclusion of MRI with LSCA as an option to be inserted in the diagnostic algorithm of challenging focal liver lesions ${ }^{7-11}$.

The LSCA approved for clinical use in Brasil in 2011 by the Brazilian Health Regulatory Agency (Anvisa) is known generically as gadoxetic acid (or gadoxetate disodium), a diagnosis medication of intravenous administration that allows for routine three-phase MRI examinations initially, followed by a hepatobiliary evaluation during the same examination ${ }^{4}$. Due to its hepatocellular uptake and half of its 50/50 biliary/ kidney excretion in healthy individuals, this contrast agent is a marker of liver tissue normofunction. In general, if there is no gadoxetic acid uptake in the hepatobiliary phase, it is possible to infer there is an absence of viable hepatocytes (as is the case, for example, in most HCCs) or absence of biliary canaliculi (observed in hepatocellular adenomas) ${ }^{4.5}$. It is recommended to carry out a clinical and/or laboratory assessment of liver and renal function prior to its administration, and its use should be avoided in patients with a creatinine clearance of less than 30 $\mathrm{ml} / \mathrm{min}$. High levels of bilirubin (above $3 \mathrm{mg} / \mathrm{dl}$ ) or ferritin, and the use of anionic drugs (such as rifampicin) can reduce the hepatobiliary effect of this contrast agent ${ }^{5.12}$. The knowledge of the biochemical properties of the LSCA has encouraged several studies based on medical genetics and protein expression, allowing for a better understanding of the in vivo behavior of this contrast agent and of the physiopathological basis of MRI findings in different focal liver lesions.

\section{CONCLUSION}

Morphofunctional MRI with liver-specific contrast agents can assist in the diagnosis of HCC in the absence of the typical characteristics in conventional examinations. Thus, despite its lower availability and its higher cost, the use of this methodology in well-indicated situations, as demonstrated here in the case of an indeterminate nodule found in the US upon CT with contrast in a patient with $\mathrm{HCV}$ without cirrhosis, is an important tool in the assessment of undetermined focal liver lesions that provides the possibility of not resorting to invasive diagnostic methods. With the accumulation of experience and dissemination of this new modality in the medical field, the use demonstrated herein and other potentials of morphofunctional MRI with liver-specific contrast as a new potential imaging tumor biomarker may be established, benefiting patients with challenging focal liver lesions.

\section{Conflict of interest}

The authors declare there are no conflicts of interest.

\section{Ethical aspects}

Project approved by the Research Ethics Committee of the institution, decision number 962.639, CAAE: 41531415.0.0000.5404 


\section{RESUMO}

O surgimento de carcinoma hepatocelular em pacientes portadores de hepatite C na ausência de cirrose é de ocorrência pouco comum. Demonstramos a importância da ressonância magnética (RM) morfofuncional com contraste hepatoespecífico por meio da descrição de uma paciente do sexo feminino, assintomática, portadora do vírus da hepatite C (VHC), que se apresentou com nódulo detectado na ultrassonografia. Realizou tomografia computadorizada inconclusiva, sem sinais de hepatopatia crônica. A RM com contraste hepatoespecífico, ao proporcionar informações funcionais, somado ao superior contraste tecidual inerente ao método, destaca-se pela maior acurácia, com a possiblidade de não se recorrer a métodos diagnósticos invasivos. Com o acúmulo de experiência e divulgação dessa nova modalidade diagnóstica no meio médico, sua utilização e outros potenciais benefícios da RM morfofuncional com contraste hepatoespecífico podem vir a se estabelecer, beneficiando pacientes com lesões hepáticas focais desafiadoras.

PALAVRAS-CHAVE: Fígado. Neoplasias hepáticas. Meios de contraste. Diagnóstico por imagem. Imagem por ressonância magnética.

\section{REFERENCES}

1. Mattos AA, Marcon PS, Araújo FS, Coral GP, Tovo CV. Hepatocellular carcinoma in a non-cirrhotic patient with sustained virological response after hepatitis C treatment. Rev Inst Med Trop Sao Paulo. 2015;57(6):519-22.

2. Miyano S, Togashi H, Shinzawa H, Sugahara K, Matsuo T, Takeda Y, et al. Occurrence of hepatocellular carcinoma 4.5 years after successful treatment with virus clearance for chronic hepatitis C. J Gastroenterol Hepatol. 1999;14(9):928-30.

3. Sewell JL, Stick KM, Monto A. Hepatocellular carcinoma after sustained virologic response in hepatitis $C$ patients without cirrhosis on a pretreatment liver biopsy. Eur | Gastroenterol Hepatol. 2009;21(2):225-9.

4. Palmucci S. Focal liver lesions detection and characterization: the advantages of gadoxetic acid-enhanced liver MRI. World J Hepatol. 2014;6(7):477-85.

5. Bormann RL, Rocha EL, Kierzenbaum ML, Pedrassa BC, Torres LR, D'Ippolito $\mathrm{G}$. The role of gadoxetic acid as a paramagnetic contrast medium in the characterization and detection of focal liver lesions: a review. Radio Bras. 2015;48(1):43-51.

6. Ronot M, Clift AK, Vilgrain V, Frilling A. Functional imaging in liver tumours | Hepatol. 2016;65(5):1017-30
7. Choi JW, Lee JM, Kim S|, Yoon JH, Baek JH, Han JK, et al. Hepatocellular carcinoma: imaging patterns on gadoxetic acid-enhanced MR images and their value as an imaging biomarker. Radiology. 2013;267(3):776-86.

8. Ye F, Liu J, Ouyang H. Gadolinium ethoxybenzyl diethylenetriamine pentaacetic acid (Gd-EOB-DTPA)-enhanced magnetic resonance imaging and multidetector-row computed tomography for the diagnosis of hepatocellular carcinoma: a systematic review and meta-analysis. Medicine (Baltimore). 2015;94(32):e1157.

9. Kudo M, Matsui O, Izumi N, lijima H, Kadoya M, Imai Y, et al. JSH consensus-based clinical practice guidelines for the management of hepatocellular carcinoma: 2014 update by the Liver Cancer Study Group of Japan. Liver Cancer. 2014;3(3-4):458-68

10. Merkle EM, Zeck C), Bartolozzi C, Bashir MR, Ba-Ssalamah A, Huppertz A, et al. Consensus report from the 7th International Forum for Liver Magnetic Resonance Imaging. Eur Radiol. 2016;26(3):674-82.

11. Ichikawa T, Sano K, Morisaka H. Diagnosis of pathologically early HCC with EOB-MRI: experiences and current consensus. Liver Cancer. 2014;3(2):97-107.

12. Van Beers BE, Pastor CM, Hussain HK. Primovist, eovist: what to expect? | Hepatol. 2012;57(2):421-9. 